\title{
Abdominal imaging findings in patients with SARS-CoV-2 infection: a scoping review
}

\author{
Kevin Lui ${ }^{1}\left[\right.$. Mitchell P. Wilson ${ }^{1} \cdot$ Gavin Low $^{1}$
}

Received: 31 July 2020 / Revised: 19 August 2020 / Accepted: 30 August 2020 / Published online: 14 September 2020

(c) Springer Science+Business Media, LLC, part of Springer Nature 2020

\begin{abstract}
Purpose This scoping review evaluated the currently available data related to abdominal imaging in the SARS-CoV-2 infection.

Method A systematic review of MEDLINE, EMBASE, SCOPUS, and Web of Science was performed from inception to July 15, 2020 using PRISMA-ScR guidelines. The review included case reports and series discussing radiologic manifestations of SARS-CoV-2 infection in abdominal imaging studies. Studies published from inception to March 31, 2020, were independently screened and reviewed by one author, and another author reviewed studies published after March 31 to July 15, 2020. Study screening and full-text review for publications before March 31, 2020, was performed by one author, and another author for publications after March 31 to July 15, 2020.

Results Thirty-six studies were included in qualitative synthesis. The prevalence of gastrointestinal symptoms is roughly $18 \%$ and includes loss of appetite, nausea, vomiting, diarrhea, and abdominal pain. Sixteen percent of COVID-19 cases may only present with gastrointestinal symptoms. Many patients presenting this way demonstrate evidence of COVID-19 incidentally through abdominal CT imaging at the lung bases. Studies published to date have also reported abdominal imaging findings including small and large bowel wall thickening, fluid-filled colon, pneumatosis intestinalis, pneumoperitoneum, intussusception, and ascites.
\end{abstract}

Conclusion Gastrointestinal manifestations and imaging manifestations of SARS-CoV-2 infection are increasingly reported and warrant specific attention during abdominal imaging.

Keywords 2019-nCoV $\cdot$ SARS-CoV-2 $\cdot$ COVID-19 $\cdot$ Gastrointestinal $\cdot$ Abdomen $\cdot$ Imaging

$\begin{array}{ll}\begin{array}{ll}\text { Abbreviation } \\ \text { SARS-Cov-2 }\end{array} & \begin{array}{l}\text { Severe acute respiratory syndrome corona- } \\ \text { virus } 2\end{array} \\ \text { COVID-19 } & \text { Coronavirus disease 2019 } \\ \text { ACE2 } & \text { Angiotensin-converting enzyme 2 } \\ \text { GI } & \text { Gastrointestinal }\end{array}$

Electronic supplementary material The online version of this article (https://doi.org/10.1007/s00261-020-02739-5) contains supplementary material, which is available to authorized users.

Kevin Lui

kslui@ualberta.ca

Mitchell P. Wilson

mitch.wilson@ualberta.ca

Gavin Low

timgy@yahoo.com

1 Department of Radiology and Diagnostic Imaging, University of Alberta, 2B2.41 WMC, 8440-112 Street NW, Edmonton, AB T6G 2B7, Canada

\section{Introduction}

Nearly 17 million people have been infected with the coronavirus disease (COVID-19) as of July 29, 2020, and more than 660,000 people have died [1]. The most common COVID-19 symptoms include fever (91\%), cough (67\%), fatigue (51\%), and dyspnea (30\%) [2]. However, gastrointestinal (GI) symptoms have been increasingly recognized in these patients [3-6] and were likely under-reported in early studies [7]. Some COVID-19 patients have presented only with GI symptoms at initial presentation, or even in the complete absence of respiratory symptoms in some cases $[8,9]$. While there is strong evidence that the digestive system can be infected by severe acute respiratory syndrome coronavirus 2 (SARS-CoV-2) [10, 11], there has been less focus on the effects of SARS-CoV-2 on extra-pulmonary systems. Few studies have identified the potential abdominal imaging features of these symptoms [12]. This scoping review aims to discuss the current literature on 
the imaging features in the abdomen in COVID-19, as well as the relevant clinical manifestations of these image findings.

\section{Methods}

This scoping review used the 22-item Preferred Reporting Items for Systematic Review and Meta-Analysis - Scoping Review (PRISMA-ScR) for guidance [13, 14]. A pre-registered protocol was not submitted prior to review.

\section{Literature Search and Selection Criteria}

MEDLINE, EMBASE, Scopus, and Web of Science databases were searched for eligible publications from inception to July 15, 2020. Variations of "COVID-19" AND "GASTROINTESTINAL" AND "IMAGING"-related title/ abstract/keywords or medical subject heading terms were performed with individual search strategies outlined in Appendix 1-4. No language restrictions were applied and language translation was performed when required. Search results were combined from each database and duplicates were removed using RefWorks. Titles and abstracts were screened for relevance, and full-text review for potentially relevant articles was then performed. To be included in the review, papers needed to address abdominal imaging findings in COVID-19-positive patients. Studies involving animal subjects were excluded. Publications from inception to March 31, 2020, were reviewed by MPW, while articles published between March 31 and July 15, 2020 were reviewed by KL. Given the broad scope of this review, a charting form was not established at the start, but one was developed after full-text review. Publications of unclear relevance were resolved by discussion and consensus between KL and MPW. Reference lists from included studies were screened to identify additional articles of interest. Forward searching of included studies was performed in Google Scholar. Ethics approval was not necessary for this review.

\section{Results}

A total of 469 articles were identified from the database search after duplicate removal. After title and abstract screening, 137 articles were identified for full-text review. In addition to studies found from included article reference lists and manual searches, 36 articles were included in qualitative synthesis. The PRISMA flow diagram is shown in Fig. 1.

\section{Incidental COVID-19 findings based on abdominal computed tomography (CT) indicated by gastrointestinal symptoms}

A wide range of GI symptoms have been reported in patients with COVID-19. A multicenter study by Pan et al. found that more than $50 \%$ of their 204 patients reported digestive symptoms including lack of appetite, diarrhea, vomiting, and abdominal pain [15]. A recent meta-analysis of 4234 patients found the prevalence of GI symptoms to be $17.6 \%$ [16]. Three case reports included hematochezia as a symptom [17-19]. There are also several case reports that describe patients that present with only GI symptoms initially or throughout the course of their entire infection [20-24]. The largest study, a single-center study by Luo et al. found that of 1141 confirmed cases of COVID-19, 16\% presented with only GI symptoms [25]. Additionally, many cases of COVID-19 have been found incidentally through abdominal imaging scans indicated by patients presenting mainly or only with GI symptoms [20, 21, 26-29]. Hossain et al found that more than $50 \%$ of their 119 patients first demonstrated evidence of COVID-19 incidentally through either an abdominal or cervical spine/neck CT [30]. Some authors now recommend radiologists to carefully review abdominal CT scans for typical COVID-19 findings at the lung bases [31, 32].

\section{Abnormal abdominal imaging findings}

Twenty-one studies have now investigated abnormal abdominal imaging findings in patients tested positive for SARSCoV-2. A summary of findings are shown in Table 1 . Ten studies of 23 patients ( 2 of which are pediatric cases) demonstrate thickening of various regions of the small and large bowel wall [17, 18, 28, 33-39]. Hyperemia and mesenteric thickening have also been observed in tandem with bowel wall thickening. Different mechanisms have been postulated for the cause of thickening in these cases. Such causes include the SARS-CoV-2 infection of bowel epithelia leading to cytokine storm and inflammation, edema, or ischemia indicated by the presence of fibrin clots.

Pneumatosis or portal vein gas has been reported on abdominal CT in 6 patients [33, 40, 41]. An additional 3 patients were reported to have pneumatosis though the diagnostic modality used is not reported [42]. The presence of pneumatosis was reported in various regions of the GI tract, including the jejunum, ileum, caecum, and right colon.

There has been one case report of abdominal CT demonstrating extensive pneumoperitoneum with free intracavitary fluid [43]. Subsequent laparotomy revealed the cause to be perforation of the sigmoid colon accompanied by reduced perfusion of the entire GI tract. The authors suggest this perforation to be the result of septic and thromboembolic phenomena, caused by the viral infection.

A rare ultrasound finding reported in pediatric cases of SARS-CoV-2 infection is ileocolic intussusception. Three separate cases have reported this imaging finding [44-46]. Another two SARS-CoV-2-positive patients have been reported to have intussusception, though it is not known if 
Fig. 1 PRISMA flow diagram of the included studies on abdominal imaging findings in patients with SARS-CoV-2 infection. Flow diagram adapted from [14]
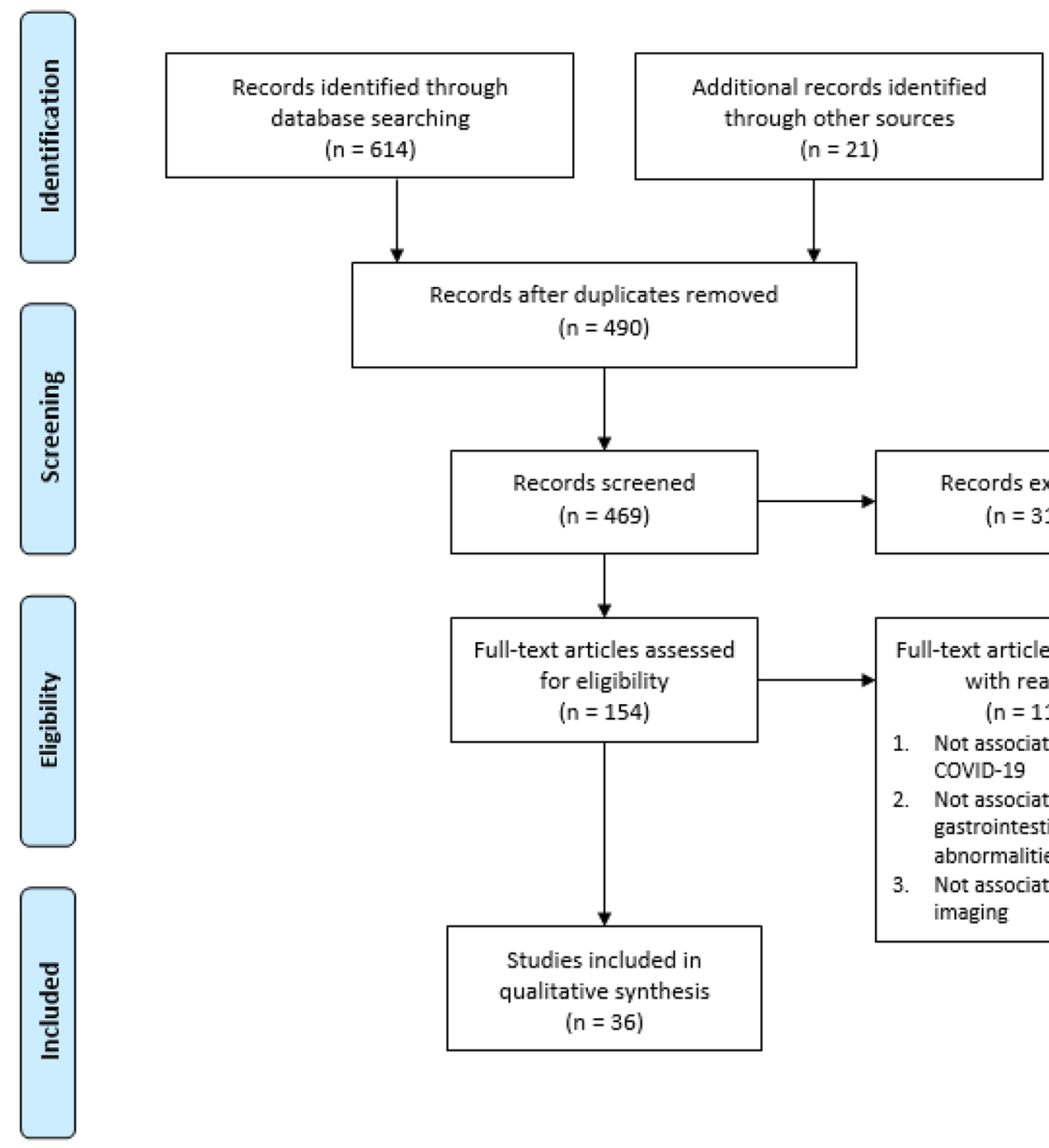

(n $=614$
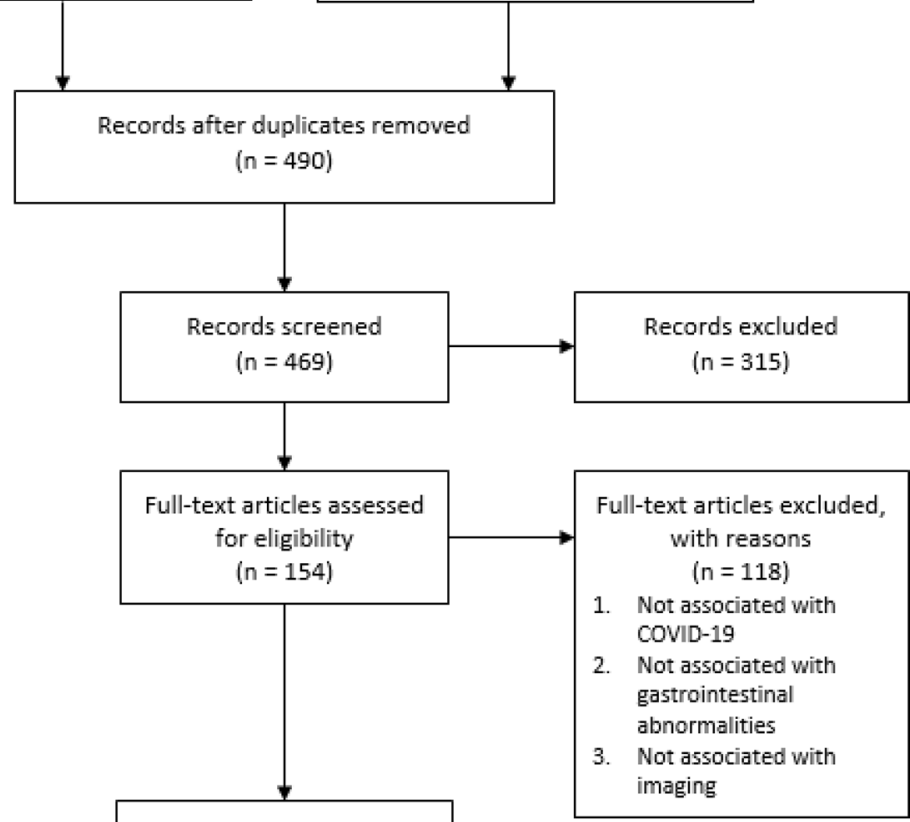

Studies included in

qualitative synthesis $(n=36)$ their condition was identified through imaging modalities $[47,48]$.

One case report involved a patient with colonic ileus and air in bowel wall on abdominal CT [35]. Behzad et al similarly reported a patient that showed ileus pattern on abdominal radiograph, along with nonspecific stranding surrounding mildly distended fluid-filled ascending colon [49]. Lastly, there has been one case of ascites found on ultrasound in a SARS-CoV-2 patient [50]. Drainage yielded 6L of fluid, and the fluid sample was tested positive for SARSCoV-2 RNA. The authors suggest that ascites infection may involve infection of ACE2 expressing cells of the esophageal epithelial cells and absorptive enterocytes [3].

\section{Discussion}

This scoping review identified 36 primary studies addressing the GI symptoms and radiologic manifestations of SARS-CoV-2 infection of the GI system. On imaging, typical GI findings have included nonspecific small and large bowel wall thickening and liquid stool throughout the bowel. Other more rare presentations such as pneumatosis intestinalis, pneumoperitoneum, and large volume ascites have also been reported. Additionally, the more typically described lung parenchymal findings have also been seen incidentally in the periphery of cross-sectional abdominal imaging. This review highlights features which can cue imaging experts to consider COVID-19 and evaluate for other features which may lead to a COVID-19 diagnosis, particularly in patients with few or no typical COVID-19 symptoms.

This scoping review is subject to some limitations. Given the broad scope of this review and the lack of detailed exclusion criteria, some imaging features may have been potentially missed. Additionally, this review may have missed relevant studies by not utilizing other search databases and exclusion of the gray literature. Furthermore, the lack of early recognition of GI symptoms [7] may limit the available literature in terms of imaging investigations indicated by GI symptoms. Investigating abdominal imaging abnormalities in COVID-19 cases presenting with both respiratory and GI symptoms may be a topic for future investigations. 


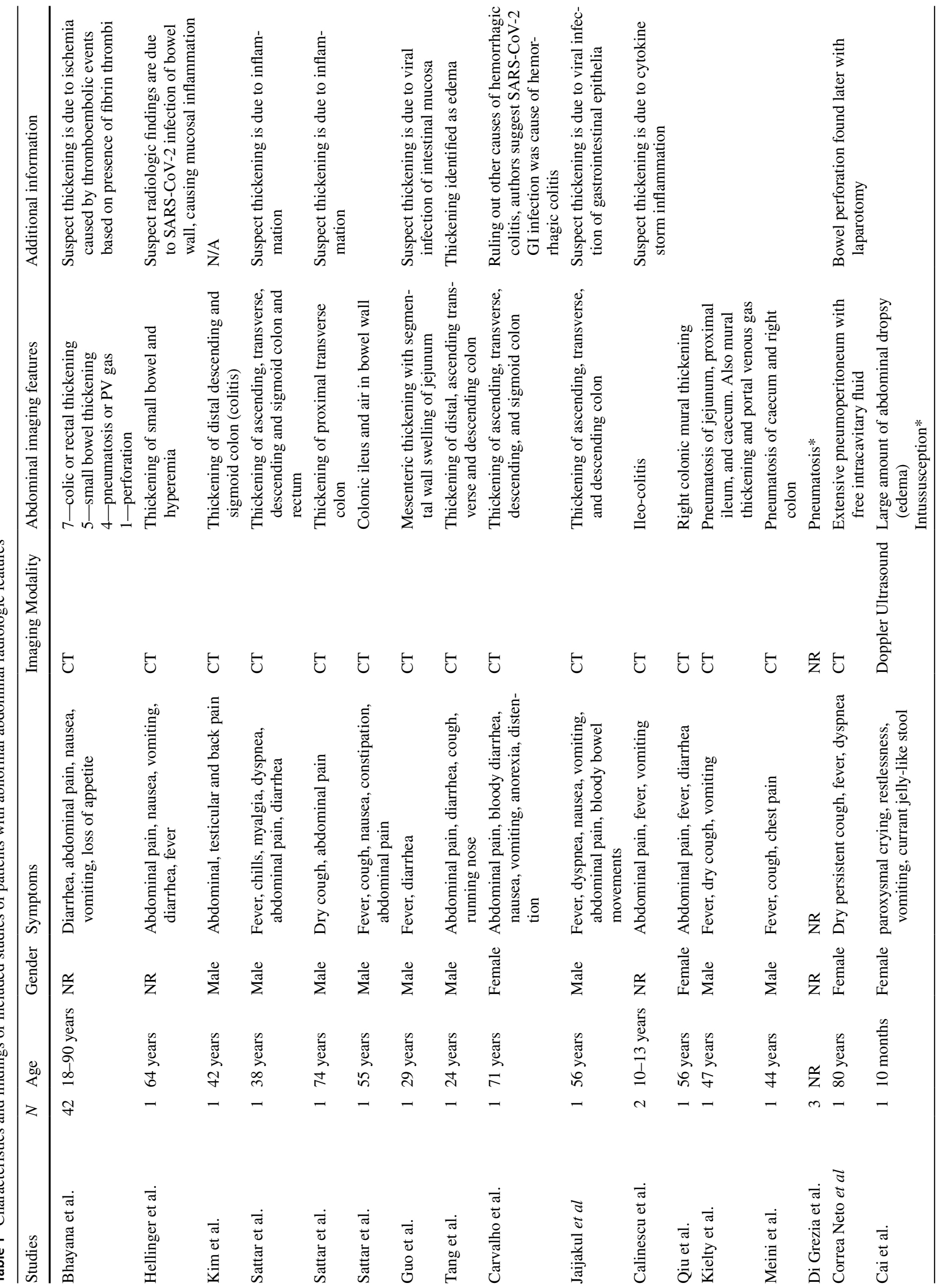




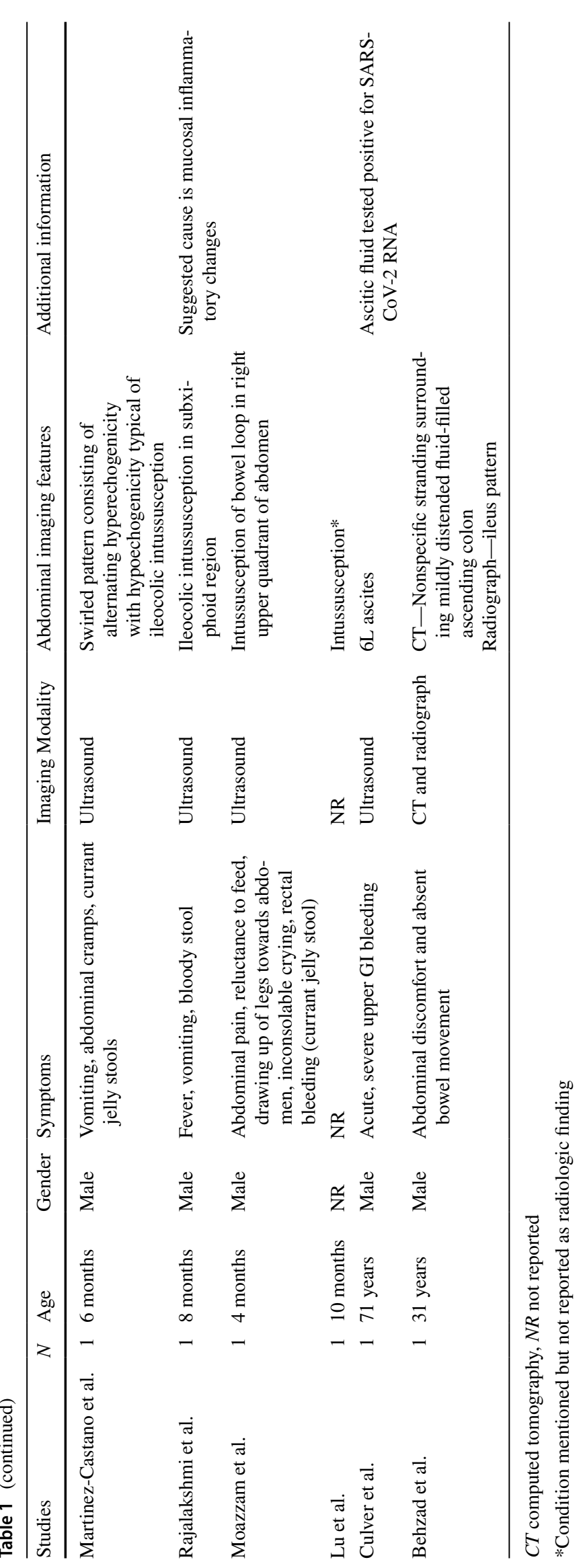




\section{Conclusion}

Gastrointestinal manifestations of COVID-19 have been increasingly recognized. Although rare, imaging features have included bowel wall thickening, fluid-filled colon, pneumatosis, pneumoperitoneum, intussusception, and ascites. Identifying these features on abdominal imaging highlight the need to consider and evaluate for other manifestations of COVID-19 such as lung parenchymal findings. In the appropriate setting, COVID-19 can be raised as a consideration, particularly in patients presenting with atypical symptoms.

Funding Studentship funding for this scoping review was provided through an Office of the Provost and VP (Academic) Summer Student award from University of Alberta Faculty of Medicine and Dentistry, and through the Radiology Endowment Fund from the University of Alberta Department of Radiology and Diagnostic Imaging.

\section{Compliance with ethical standards}

Conflicts of interest The authors have no relevant conflicts of interest to declare.

Ethics approval The study is exempt from ethical approval at our institution as all reviewed publications included anonymized data and have acquired appropriate institutional ethical approval where necessary.

\section{References}

1. Johns Hopkins Corona Virus Resource Center (2020) Maps and Trends. https://coronavirus.jhu.edu/map.html

2. Yang J, Zheng Y, Gou X, Pu K, Chen Z, Guo Q, Ji R, Wang H, Wang Y, Zhou Y (2020) Prevalence of comorbidities in the novel Wuhan coronavirus (COVID-19) infection: a systematic review and meta-analysis. Int J: Infect Dis 94:91-95

3. Tian Y, Rong L, Nian W, He Y (2020) Review article: gastrointestinal features in COVID-19 and the possibility of faecal transmission. Alimentary pharmacology \& therapeutics 51:843-851

4. Jin X, Lian J, Hu J, Gao J, Zheng L, Zhang Y, Hao S, Jia H, Cai $\mathrm{H}$, Zhang X, Yu G, Xu K, Wang X, Gu J, Zhang S, Ye C, Jin C, Lu Y, Yu X, Yu X, Huang J, Xu K, Ni Q, Yu C, Zhu B, Li Y, Liu J, Zhao H, Zhang X, Yu L, Guo Y, Su J, Tao J, Lang G, Wu X, Wu W, Qv T, Xiang D, Yi P, Shi D, Chen Y, Ren Y, Qiu Y, Li L, Sheng J, Yang Y (2020) Epidemiological, clinical and virological characteristics of 74 cases of coronavirus-infected disease 2019 (COVID-19) with gastrointestinal symptoms. Gut 69:1002-1009

5. Wong SH, Lui RN, Sung JJ (2020) Covid-19 and the digestive system. Journal of gastroenterology and hepatology 35:744-748

6. Zhou Z, Zhao N, Shu Y, Han S, Chen B, Shu X (2020) Effect of gastrointestinal symptoms on patients infected with COVID-19. Gastroenterology 158:2294-2297

7. Liang W, Feng Z, Rao S, Xiao C, Xue X, Lin Z, Zhang Q, Qi W (2020) Diarrhoea may be underestimated: a missing link in 2019 novel coronavirus. Gut 69:1141-1143

8. An P, Chen H, Jiang X, Su J, Xiao Y, Ding Y, Ren H, Ji M, Chen Y, Chen W (2020) Clinical features of 2019 novel coronavirus pneumonia presented gastrointestinal symptoms but without fever onset. Lancet Epub ahead of print

9. Collaborative $\mathrm{C}$ (2020) Global guidance for surgical care during the COVID-19 pandemic. Br.J.Surg 107. https://doi.org/10.1002/ bjs. 11646

10. Hindson J (2020) COVID-19: faecal-oral transmission?. Nature Reviews Gastroenterology \& Hepatology 17:259

11. Zhang H, Kang Z, Gong H, Xu D, Wang J, Li Z, Li Z, Cui X, Xiao J, Zhan J, Meng T, Zhou W, Liu J, Xu H (2020) Digestive system is a potential route of COVID-19: an analysis of single-cell coexpression pattern of key proteins in viral entry process. Gut 69:1010-1018

12. Wilson MP, Katlariwala P, Low G (2020) Potential implications of novel coronavirus disease (COVID-19) related gastrointestinal symptoms for abdominal imaging. Radiography 26:274

13. Tricco AC, Lillie E, Zarin W, O'Brien KK, Colquhoun H, Levac D, Moher D, Peters MDJ, Horsley T, Weeks L, Hempel S, Akl EA, Chang C, McGowan J, Stewart L, Hartling L, Aldcroft A, Wilson MG, Garritty C, Lewin S, Godfrey CM, Macdonald MT, Langlois EV, Soares-Weiser K, Moriarty J, Clifford T, Tunçalp Ö, Straus SE (2018) PRISMA Extension for Scoping Reviews (PRISMA-ScR): Checklist and Explanation. Annals of internal medicine 169:467-473

14. Moher D, Liberati A, Tetzlaff J, Altman DG, The PG (2009) Preferred Reporting Items for Systematic Reviews and Meta-Analyses: The PRISMA Statement. PLOS Medicine 6:e1000097

15. Pan L, Mu M, Yang P, Sun Y, Wang R, Yan J, Li P, Hu B, Wang J, Hu C, Jin Y, Niu X, Ping R, Du Y, Li T, Xu G, Hu Q, Tu L (2020) Clinical Characteristics of COVID-19 Patients With Digestive Symptoms in Hubei, China: A Descriptive, Cross-Sectional, Multicenter Study. The American journal of gastroenterology 115:766-773

16. Cheung KS, Hung IFN, Chan PPY, Lung KC, Tso E, Liu R, Ng YY, Chu MY, Chung TWH, Tam AR, Yip CCY, Leung K, Fung AY, Zhang RR, Lin Y, Cheng HM, Zhang AJX, To KKW, Chan K, Yuen K, Leung WK (2020) Gastrointestinal Manifestations of SARS-CoV-2 Infection and Virus Load in Fecal Samples From a Hong Kong Cohort: Systematic Review and Meta-analysis. Gastroenterology 159:81-95

17. Jaijakul S. Colitis as a Sole Presentation of SARS-CoV-2 Infection: Case Report. SN Comprehensive Clinical Medicine 2020; 2: $879-881$

18. Carvalho A, Alqusairi R, Adams A, Paul M, Kothari N, Peters S, DeBenedet AT (2020) SARS-CoV-2 Gastrointestinal Infection Causing Hemorrhagic Colitis: Implications for Detection and Transmission of COVID-19 Disease. American Journal of Gastroenterology 115:942-946

19. Guotao L, Xingpeng Z, Zhihui D, Huirui W (2020) SARS-CoV-2 infection presenting with hematochezia. Medecine et Maladies Infectieuses 50:293-296

20. Pazgan-Simon M, Rorat M, Buczynska I, Zinczuk A, Simon K (2020) Gastrointestinal symptoms as the first, atypical indication of severe acute respiratory syndrome coronavirus 2 infection. Polish Archives Of Internal Medicine 130:338-339

21. Xiao N, Abboud S, McCarthy DM, Parekh N (2020) Incidentally discovered COVID-19 in low-suspicion patients-a threat to front line health care workers. Emergency Radiology. https://dx.doi. org/10.1007/s10140-020-01792-3

22. Yang X, Zhao J, Yan Q, Zhang S, Wang Y, Li Y (2020) A case of COVID-19 patient with the diarrhea as initial symptom and literature review. Clinics and Research in Hepatology and Gastroenterology. http://dx.doi.org/10.1016/j.clinre.2020.03.013

23. Gahide G, Frandon J, Vendrell JF (2020) COVID-19 patients presenting with afebrile acute abdominal pain. ClinMed 20:e4-6

24. Guan W, Ni Z, Hu Y, Liang W, Ou C, He J, Liu L, Shan H, Lei C, Hui DSC, Du B, Li L, Zeng G, Yuen K, Chen R, Tang C, Wang 
T, Chen P, Xiang J, Li S, Wang J, Liang Z, Peng Y, Wei L, Liu Y, Hu Y, Peng P, Wang J, Liu J, Chen Z, Li G, Zheng Z, Qiu S, Luo J, Ye C, Zhu S, Zhong N. Clinical Characteristics of Coronavirus Disease 2019 in China. N Engl J Med 2020; 382: 1708-1720

25. Luo S, Zhang X, Xu H. Don't Overlook Digestive Symptoms in Patients With 2019 Novel Coronavirus Disease (COVID-19). Clinical Gastroenterology and Hepatology 2020; 18: 1636-1637

26. Sendi AA, Saggat DF, Alzahrani SJ. (2020) Incidental typical COVID-19 appearance on the lung bases, visualized at abdominal CT for a patient that presented with abdominal pain and nausea. Radiol.Case Rep. 15:1238-1241. https://dx.doi.org/10.1016/j.radcr 2020.05 .039

27. Siegel A, Chang PJ, Jarou ZJ, Paushter DM, Harmath CB, Arevalo JB, Dachman A (2020) Lung Base Findings of Coronavirus Disease (COVID-19) on Abdominal CT in Patients With Predominant Gastrointestinal Symptoms. American Journal of Roentgenology. https://dx.doi.org/10.2214/AJR.20.23232

28. Kim J, Thomsen T, Sell N, Goldsmith AJ (2020) Abdominal and testicular pain: An atypical presentation of COVID-19. American Journal of Emergency Medicine 38:1542.e1-1542.e3

29. Dane B, Brusca-Augello G, Kim D, Katz DS (2020) Unexpected Findings of Coronavirus Disease (COVID-19) at the Lung Bases on Abdominopelvic CT. American Journal of Roentgenology. https://doi.org/10.2214/AJR.20.23240

30. Hossain R, Lazarus MS, Roudenko A, Dako F, Mehta V, Alis J, Zalta B, Lei B, Haramati LB, White CS (2020) CT Scans Obtained for Nonpulmonary Indications: Associated Respiratory Findings of COVID-19. Radiology Epub ahead of print

31. Lang M, Som A, Mendoza DP, Flores EJ, Li MD, Shepard JO, Little BP (2020) Detection of Unsuspected Coronavirus Disease 2019 Cases by Computed Tomography and Retrospective Implementation of the Radiological Society of North America/Society of Thoracic Radiology/American College of Radiology Consensus Guidelines. J.Thorac.Imaging Epub ahead of print

32. Redmond CE, Nicolaou S, Berger FH, Sheikh AM, Patlas MN (2020) Emergency Radiology During the COVID-19 Pandemic: The Canadian Association of Radiologists Recommendations for Practice. Canadian Association of Radiologists Journal Epub ahead of print

33. Bhayana R, Som A, Li MD, Carey DE, Anderson MA, Blake MA, Catalano O, Gee MS, Hahn PF, Harisinghani M, Kilcoyne A, Lee SI, Mojtahed A, Pandharipande PV, Pierce TT, Rosman DA, Saini S, Samir AE, Simeone JF, Gervais DA, Velmahos G, Misdraji J, Kambadakone A (2020) Abdominal Imaging Findings in COVID-19: Preliminary Observations. Radiology 201908

34. Hellinger JC, Sirous R, Hellinger RL, Krauthamer A (2020) Abdominal presentation of covid-19. Applied Radiology 49:24-26

35. Sattar Y, Connerney M, Rauf H, Saini M, Ullah W, Mamtani S, Syed U, Luddington S, Walfish A (2020) Three Cases of COVID19 Disease With Colonic Manifestations. American Journal of Gastroenterology 115:948-950

36. Guo Y, Hu X, Yu F, Chen J, Zheng W, Liu J, Zeng P (2020) Abdomen CT findings in a COVID-19 patient with intestinal symptoms and possibly false negative RT-PCR before initial discharge. Quantitative Imaging in Medicine and Surgery 10:1158-1161

37. Tang L, Cheng X, Tian C, Wang R, Zhou H, Wu W, Yan L, Zeng $X$ (2020) Computed tomography (CT) intestinal alterations of Coronavirus Disease 2019 (COVID-19) from the imaging perspective: A case description. Quantitative Imaging in Medicine and Surgery 10:1145-1149

38. Calinescu AM, Vidal I, Grazioli S, Lacroix L, Wildhaber BE (2020) Comment on "Beware of Too Aggressive Approach in
Children With Acute Abdomen During COVID-19 Outbreak!”. Annals of Surgery https://doi.org/10.1097/SLA.0000000000 004100

39. Qiu H, Wander P, Bernstein D, Satapathy SK (2020) Acute on chronic liver failure from novel severe acute respiratory syndrome coronavirus 2 (SARS-CoV-2). Liver International 40:1590-1593

40. Meini S, Zini C, Passaleva MT, Frullini A, Fusco F, Carpi R, Piani F (2020) Pneumatosis intestinalis in COVID-19. BMJ Open Gastroenterology 7

41. Kielty J, Duggan WP, O'Dwyer M (2020) Extensive pneumatosis intestinalis and portal venous gas mimicking mesenteric ischaemia in a patient with SARS-CoV-2. Annals of the Royal College of Surgeons of England e1-e3

42. Di Grezia M, Fransvea P, Santullo F, Tirelli F, Fico V, Mirco P, Cozza V, La Greca A, Sganga G (2020) Intra-abdominal hypertension as a trigger of "gut failure" in SARS-CoV-2 infection: Effect of open abdomen (OA) and negative pressure therapy (NPT) on respiratory and gastrointestinal (GI) function. Medical hypotheses 144: 1099542

43. Corrêa Neto, I. J. F., Viana KF, Silva, M. B. S. D., Silva LMD, Oliveira GD, Cecchini, A. R. D. S., Rolim AS, Robles L (2020) Perforated acute abdomen in a patient with COVID-19: an atypical manifestation of the disease. Journal of Coloproctology 40:269-272

44. Martinez-Castano I, Calabuig-Barbero E, Gonzalvez-Pinera J, Lopez-Ayala JM (2020) COVID-19 Infection Is a Diagnostic Challenge in Infants With Ileocecal Intussusception. Pediatric emergency care 36:e368

45. Rajalakshmi L, Satish S, Nandhini G, Ezhilarasi S (2020) UNUSUAL PRESENTATION OF COVID-19 AS INTUSSUSCEPTION. Indian Journal of Practical Pediatrics 22:236

46. Moazzam Z, Salim A, Ashraf A, Jehan F, Arshad M (2020) Intussusception in an infant as a manifestation of COVID-19. Journal of Pediatric Surgery Case Reports 59

47. Lu X, Zhang L, Du H, Zhang J, Li YY, Qu J, Zhang W, Wang Y, Bao S, Li Y, Wu C, Liu H, Liu D, Shao J, Peng X, Yang Y, Liu Z, Xiang Y, Zhang F, Silva RM, Pinkerton KE, Shen K, Xiao H, $\mathrm{Xu} \mathrm{S}$, Wong GWK (2020) SARS-CoV-2 Infection in Children. N Engl J Med 382:1663-1665

48. Cai X, Ma Y, Li S, Chen Y, Rong Z, Li W (2020) Clinical Characteristics of 5 COVID-19 Cases With Non-respiratory Symptoms as the First Manifestation in Children. Frontiers in Pediatrics 8

49. Behzad S, Aghaghazvini L, Radmard AR, Gholamrezanezhad A (2020) Extrapulmonary manifestations of COVID-19: Radiologic and clinical overview. Clinical imaging 66:35-41

50. Culver A, Arbelot C, Bechis C, Cassir N, Leone M (2020) First description of SARS-CoV-2 in ascites. IDCases 21:e00836

51. Wolters Kluwer (2020) COVID-19 TOOLS \& RESOURCES FOR CLINICIANS. Expert Search Strategies. http://tools.ovid. com/coronavirus/. Accessed 22 June 2020

52. Campbell S (2020) Search Hedge to Retrieve Studies related to COVID-19 from the SCOPUS Database. https://guides.libra ry.ualberta.ca/health-sciences-search-filters/subject-filters. Accessed 22 June 2020

Publisher's Note Springer Nature remains neutral with regard to jurisdictional claims in published maps and institutional affiliations. 